\title{
Advances in the synthesis of tetrazoles coordinated to metal ions
}

\author{
Elena A. Popova,* Rostislav E. Trifonov and Vladimir A. Ostrovskii \\ St. Petersburg State Institute of Technology (Technical University), Moskovsky av. 26 \\ 190013 St. Petersburg, Russian Federation \\ E-mail:popova_e_a@bk.ru
}

\begin{abstract}
The principal methods of synthesis of tetrazole-containing coordination complexes are systematized and generalized.
\end{abstract}

Keywords: Tetrazoles, coordination complexes, synthesis

\section{Table of Contents}

1. Introduction

2. Reactions of Tetrazoles with Metal Bases and Salts

2.1. Reactions of NH-5R-tetrazoles with bases and metal salts

2.2. Reactions of $\mathrm{N}^{1}$-substituted tetrazoles with metal salts

2.3. Reactions of $\mathrm{N}^{2}$-substituted tetrazoles with metal salts

3. Substitution of Ligands for Tetrazoles in Coordination Compounds

4. Metal-promoted Cycle Formation

5. Conclusions

6. References

\section{Introduction}

In recent years the number of publications and patents describing the targeted synthesis, investigations of the structure and physicochemical properties of metal derivatives including in their structure tetrazole heterocyclic fragment $\mathbf{1}$ has grown intensely.<smiles>[R]c1nnn[nH]1</smiles> 
This is due to the wide range of practical applications of these compounds. Main applications of the tetrazole metal derivatives are as follows: organic synthesis, gas-generating compositions, and some others. ${ }^{1,2}$ One of the most important fields where tetrazole-containing coordination complexes are used is medical chemistry. The high physiological activity and low toxicity of tetrazoles makes it possible to regard their metal complexes as substances of versatile biochemical and pharmaceutical destination. For instance, complexes of $\mathrm{Cu}$ (II), $\mathrm{Co}(\mathrm{II}), \mathrm{Ni}$ (II), and $\mathrm{Zn}$ (II) containing in their composition as a ligand cefazolin antibiotic (in deprotonated form), show higher antibacterial activity in vitro with respect to some bacterial strains than the noncoordinated cefazolin. ${ }^{2-4}$ Besides, tetrazoles may be used as components of filtering materials of the new generation for the purification of biological fluids (blood, lymph etc.) from heavy metals ions. ${ }^{5}$

The capability of tetrazoles to take part in the formation of stable complexes with cations of nonferrous metals underlies modern promising anticorrosion compositions for the protection of metal surfaces from the atmospheric corrosion and various aggressive environments. It was shown that combined application of 5-phenyltetrazole and benzotriazole salts in water environment resulted in synergistic effect of steel protection from corrosion. ${ }^{6}$

Several main types of tetrazole metal derivatives are known where the metal atom can be linked to the heterocycle by covalent, ionic, or coordination bond, and therewith the heterocycle can be included in the composition of the molecule in a neutral, anionic, or cationic form. ${ }^{2}$

Up to now a fairly large amount of material has been accumulated on the synthesis and properties of the tetrazole-containing metal derivatives. The data on the preparation methods and application of organometallic tetrazole derivatives including 5-metallotetrazoles and tetrazoles containing a metal-carbon bond in the substituent, and also organotintetrazoles are described and generalized in a previous review. ${ }^{7}$ In this article we focus our attention on summarizing results of research on the main preparation procedures for tetrazole-containing metal complexes obtained from anionic and neutral tetrazole forms and containing a metal-nitrogen bond.

Three main methods of synthesis of the tetrazole-containing complexes may be singled out: -Reactions of tetrazoles with metal bases or salts;

-Substitution of ligands for tetrazoles in coordination compounds;

-Metal-promoted azidation of nitriles

\section{Reactions of Tetrazoles with Metal Bases and Salts}

\subsection{Reactions of NH-5R-tetrazoles with metal bases and salts}

The method of preparation of tetrazole-containing metal derivatives based on direct reaction of tetrazoles with metal bases or salts has been known for over a half century. ${ }^{1,2}$ Numerous studies were dedicated to the synthesis, structural features and some properties of metal derivatives containing 5-substituted tetrazole fragment. ${ }^{8-28}$

Many chemical and physicochemical properties of tetrazoles are known to be associated with their capability to act as acids and bases. For instance, among other thermally and chemically 
stable azoles the $\mathrm{NH}$-unsubstituted tetrazoles posses a high acidity and very low basicity. ${ }^{1}$ In this connection, just the ability of the NH-unsubstituted 5R-tetrazoles to act as NH-acids underlies the reactivity of these compounds towards various bases (hydroxides, alcoholates, hydrides of alkali and alkaline-earth metals). This results in the formation of the corresponding salts, tetrazolates. It should be stressed that in the reactions of NH-5R-tetrazoles 1 with hydroxides of alkali and alkaline-earth metals and as a result of the deprotonation of the tetrazole ring, these salt-like compounds possess predominantly ionic structure 2 (Scheme 1). ${ }^{2}$ Mainly, these reactions are carried out in aqueous medium, in ethanol or acetonitrile.

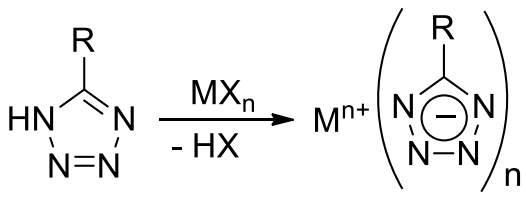

1

2

$M$ is alkali or alkaline-earth metal, $n=1,2 ; X=H, O H$, OAlk.

\section{Scheme 1}

The reactions of $\mathrm{NH}-5 \mathrm{R}$-tetrazoles with organometallic bases and oxides lead to the formation of metal compounds having a more complex structure due to the formation of two types of metal-nitrogen bonds: covalent and coordination ones. ${ }^{2}$ Thus, according to X-ray diffraction, the tetrazolate ligands in compound $\mathbf{4}$ may coordinate in a tridentate mode through N1, N2, N3 nitrogen atoms (Scheme 2). ${ }^{8}$

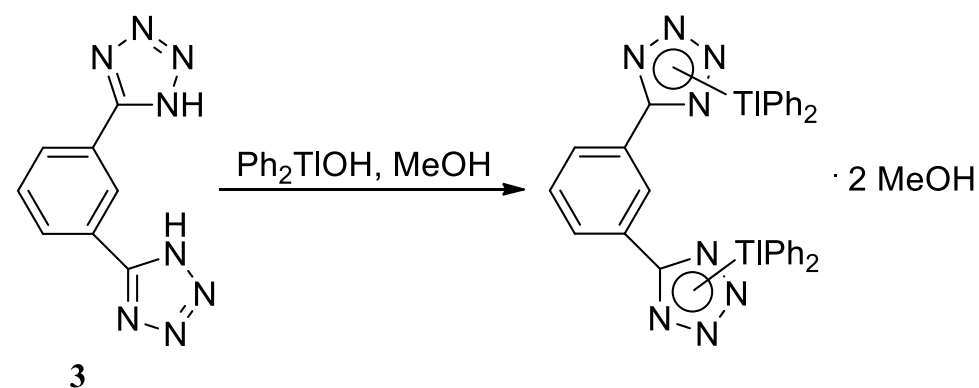

4

\section{Scheme 2}

Using reactions of $\mathrm{NH}$-tetrazoles with various metal salts (chlorides, nitrates, sulfates, acetates, etc.) numerous tetrazole-containing coordination compounds were prepared and characterized. The so-formed compounds may include the solvent molecules and also the initial reagents. In addition, the product composition depends on the ratio of the initial reagents. These complexes are often obtained in water or water-alcohol solutions at room temperature. The target compounds separate as precipitates poorly soluble or virtually insoluble in the most common 
organic solvents. ${ }^{2}$ The tetrazole-containing coordination compounds form various structures and as a rule exist as one-, two-, or three-dimensional coordination polymers. For instance, the reaction of $\mathrm{Zn}(\mathrm{II})$ and $\mathrm{Cd}(\mathrm{II})$ salts with bis(tetrazol-5-yl)alkanes afforded a new series of tetrazole-containing coordination polymers: $\left[\mathrm{Zn}_{2}(1,2-\text { bis(tetrazol-5-yl)ethane })_{2}\left(\mathrm{H}_{2} \mathrm{O}\right)\right]_{\mathrm{n}},\left[\mathrm{Cd}_{2}(1,2-\right.$ bis(tetrazol-5-yl)ethane) $\left.\mathrm{Cl}_{2}\left(\mathrm{H}_{2} \mathrm{O}\right)\right]_{\mathrm{n}}, \quad\left[\mathrm{Cd}_{3}\left(1,2-\text { bis }(\text { tetrazol-5-yl)ethane })_{3}\left(\mathrm{H}_{2} \mathrm{O}\right)_{12}\right]_{\mathrm{n}}, \quad[\mathrm{Zn}(1,2-\right.$ bis(tetrazol-5-yl)propane) $]_{n}, \quad\left[\mathrm{Cd}_{2}(1,2-\text {-bis(tetrazol-5-yl)propane }) \mathrm{Cl}_{2}\right]_{\mathrm{n}}, \quad\{[\mathrm{Zn}(1,2-$ bis(tetrazol-5yl)butane $\left.\left.)\left(\mathrm{H}_{2} \mathrm{O}\right)_{4}\right] \cdot\left(\mathrm{H}_{2} \mathrm{O}\right)_{2}\right\}_{\mathrm{n}}, \quad\left\{\left[\mathrm{Cd}_{3}(1,2 \text {-bis(tetrazole-5-yl)butane })_{2} \mathrm{Cl}_{4}\right] \cdot\left(\mathrm{H}_{2} \mathrm{O}\right)_{4}\right\}_{\mathrm{n}} \cdot{ }^{29} \quad$ These complexes have diverse structures: one-dimensional chains (1D), two-dimensional layers (2D), and three-dimensional coordination polymers (3D).

Into the composition of the arising complex compounds the tetrazole moiety enters as a rule in the deprotonated form (tetrazolate anion). For example, $\mathrm{Zn}$ (II) cation in the reaction with 2,3diethyl-5,6-di(1H-tetrazol-5-yl)pyrazine $\mathbf{5}$ coordinates to the nitrogen atoms of the tetrazole rings forming the respective tetrazolate complex 6 (Scheme 3 ). ${ }^{30}$ In conformity with X-ray analysis, complex 6 has a dinuclear structure in which $\mathrm{Zn}$ (II) is four-coordinated to furnish a distorted tetrahedral geometry and in the crystal structure the dinuclear units are further assembled to form a three-dimensional (3D) framework by hydrogen bonds.

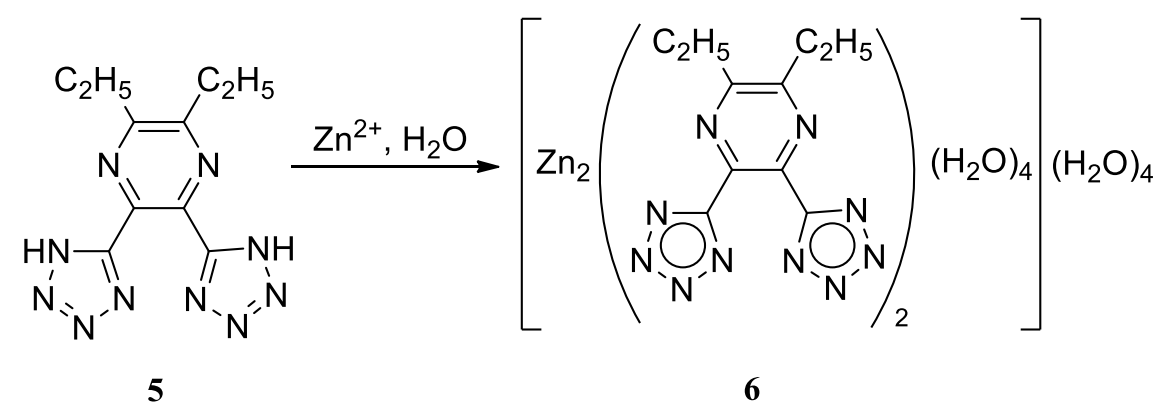

\section{Scheme 3}

In several studies the complexes containing in their composition neutral form of 5Rtetrazoles were described. ${ }^{31}$ For instance, the reaction of cobalt chloride hexahydrate $\mathrm{CoCl}_{2} \cdot 6 \mathrm{H}_{2} \mathrm{O}$ with 1,3-ditetrazol-5-ylbenzene in the mixture acetonitrile/ethanol afforded tetrazole-containing coordination compound $\left[\mathrm{Co}\left(\mathrm{C}_{8} \mathrm{H}_{6} \mathrm{~N}_{8}\right)_{2}\left(\mathrm{H}_{2} \mathrm{O}\right)_{2}\left(\mathrm{CH}_{3} \mathrm{CN}\right)_{2}\right] \mathrm{Cl}_{2}$. Both tetrazole rings in the molecule of the coordinated 1,3-ditetrazol-5-ylbenzene are present in the $1 H$ tautomeric form.

Another example of complexes containing in their composition the tetrazole ring in neutral form is described in the work of Klapötke and coauthors. ${ }^{32}$ By the reaction of $N, N$-bis $(1 H$ tetrazol-5-yl)-amine monohydrate 7 with copper salts $\mathrm{CuX}_{2} \cdot \mathrm{yH}_{2} \mathrm{O}\left(\mathrm{X}=\mathrm{Cl}, \mathrm{y}=2 ; \mathrm{X}=\mathrm{ClO}_{4}, \mathrm{y}=6\right.$; $\mathrm{X}=\mathrm{NO}_{3}, \mathrm{y}=2$ ) a series of coordination compounds 8-10 was obtained (Scheme 4). 


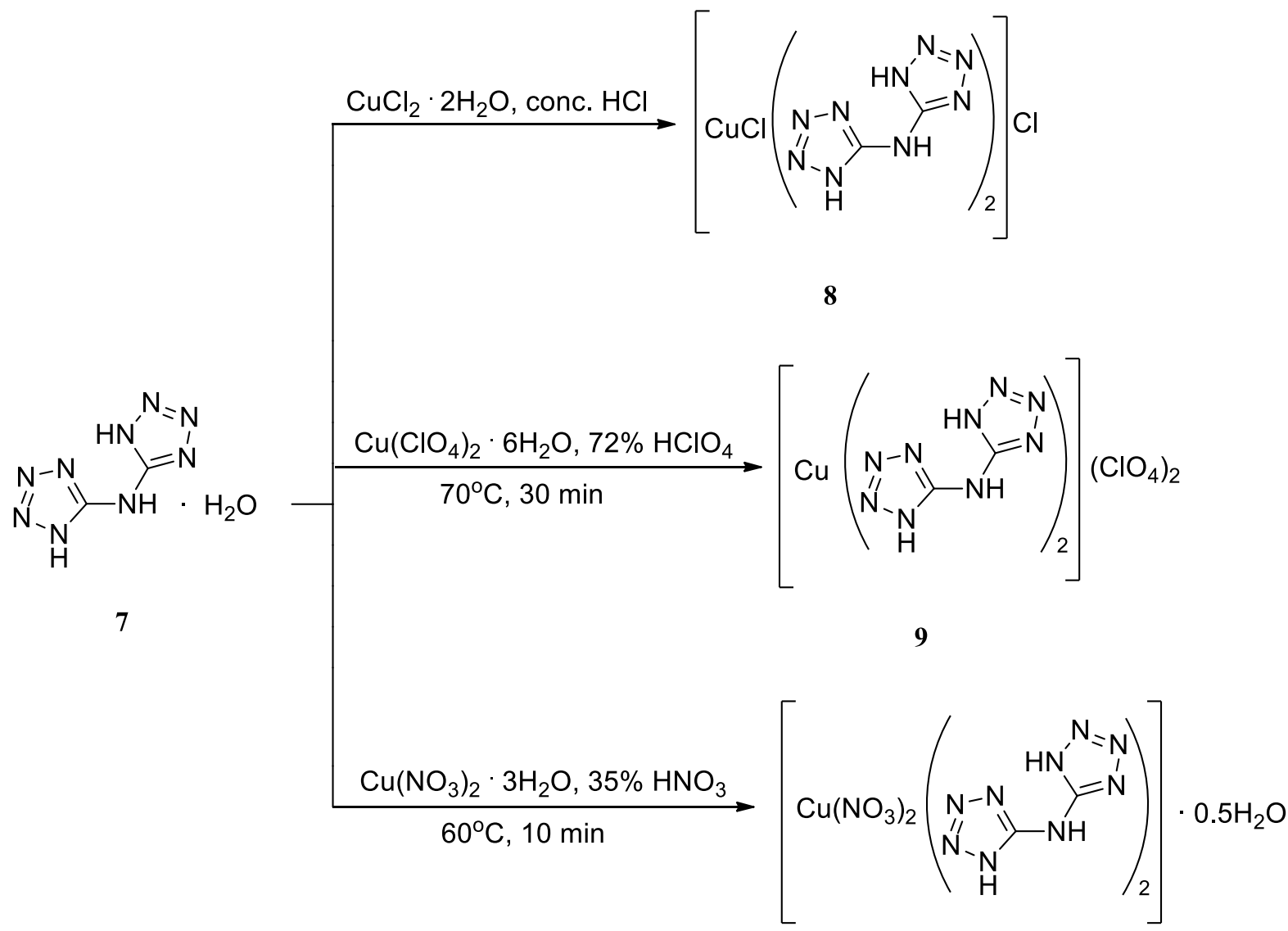

10

\section{Scheme 4}

The composition of the described $\mathrm{Cu}$ (II) complexes 8-10 depended not only on the reaction conditions (solvent, concentration of the corresponding acid, temperature), but also on the duration of the crystal growth. In correspondence with X-ray diffraction, in the complex 8 the copper atom is five coordinated by four nitrogen atoms and one chloride ligand. At the same time, in the complex $9 \mathrm{Cu}$ atom displays a distorted octahedral geometry. It is positioned on an inversion centre bonded to four nitrogen atoms of the two ligands in the equatorial plane. ${ }^{32}$ 


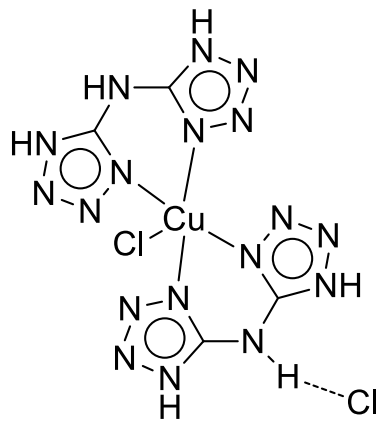

8

Uranium(VI) salts as a rule do not form coordination bonds with the nitrogen atoms of the tetrazole ring. The preparation of tetrazole-containing U(VI) complexes is possible when the oxygen-containing substituent is present at the tetrazole ring. For instance, the synthesis of complex $\left.\left[\mathrm{UO}_{2}(5-(N \text {-acetato(4-pyridyl })) \text { tetrazolate }\right)_{2} \cdot\left(\mathrm{H}_{2} \mathrm{O}\right)_{3}\right] \mathbf{1 1}$ by the reaction of potassium 5$\left(N\right.$-acetato(4-pyridyl))tetrazolate with uranyl nitrate hexahydrate $\mathrm{UO}_{2}\left(\mathrm{NO}_{3}\right)_{2} \cdot 6 \mathrm{H}_{2} \mathrm{O}$ in water at $100{ }^{\circ} \mathrm{C}$ has been described. ${ }^{33}$ According to X-ray analysis, the uranium atom formed U-O bonds with the oxygen atoms of the carbonyl groups of the ligands.

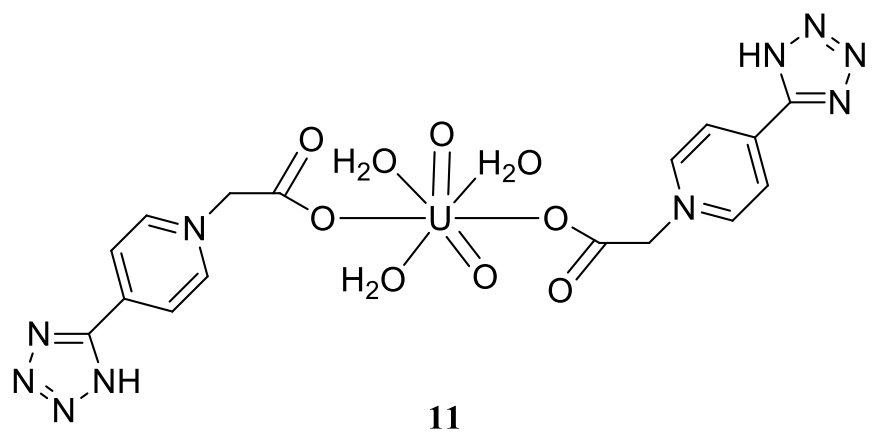

At the same time the reaction of potassium 5-( $N$-acetato(4-pyridyl))tetrazolate with zinc(II) perchlorate hexahydrate $\mathrm{Zn}\left(\mathrm{ClO}_{4}\right)_{2} \cdot 6 \mathrm{H}_{2} \mathrm{O}$ in water resulted in the formation of the complex [ $\mathrm{Zn}\left(5-(\mathrm{N} \text {-acetato(4-pyridyl))tetrazolate })_{2} \cdot\left(\mathrm{H}_{2} \mathrm{O}\right)_{2}\right] \cdot \mathrm{H}_{2} \mathrm{O}$ where zinc atoms coordinate both to oxygen atoms of the carbonyl groups and the $\mathrm{N} 2$ atoms of the tetrazole rings. ${ }^{33}$

\subsection{Reactions of $\mathbf{N}^{1}$-substituted tetrazoles with metal salts}

$\mathrm{N}^{1}$-Substituted tetrazoles lack the labile hydrogen atom in the ring (unlike the NH-unsubstituted tetrazoles) and therefore do not exhibit acidic properties, being only weak bases ( $\left.K_{\mathrm{BH}_{+}}{ }^{-9} \div-2\right){ }^{1}$ Therefore the $\mathrm{N}^{1}$ - and $\mathrm{N}^{2}$-substituted tetrazoles are involved into the formation of metal derivatives exclusively in the neutral form. ${ }^{34-40}$ The metal ions can bind to the nitrogen atoms of the tetrazole ring by the coordination or the covalent type. It should be noted that in the $\mathrm{N}^{1}$ substituted tetrazoles the highest basicity is at the N4 atom; therefore, just this atom of the tetrazole ring in most cases takes part in the formation of the coordination bond. 
$\mathrm{N}^{1}$-Substituted tetrazoles relatively readily enter into reactions with transition metal halides (Scheme 5) giving adducts whose structure may be regarded as belonging to the molecular type; also many among them are polymers and precipitate from solutions forming insoluble substances. ${ }^{41}$ The choice of a solvent for such reactions is based on its electron-donor activity, the ability to dissolve the initial components, and the capability to act as a precipitating agent or the medium for crystallization of the final products. As a rule, the complex formation with $\mathrm{N}^{1}$ substituted tetrazoles proceeds easily at room temperature in weakly coordinating solvents (alcohols, acetone, diethyl ether, acetonitrile, etc.) with the formation of a solid complex compound. $^{2}$

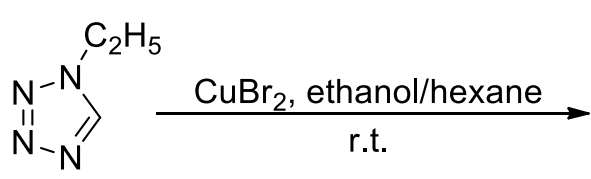

12<smiles></smiles>

13

\section{Scheme 5}

When the coordination compounds form involving 1,5-disubstituted tetrazoles (Scheme 6) the coordination predominantly occurs also through the N4 atom of the tetrazole ring. ${ }^{42}$

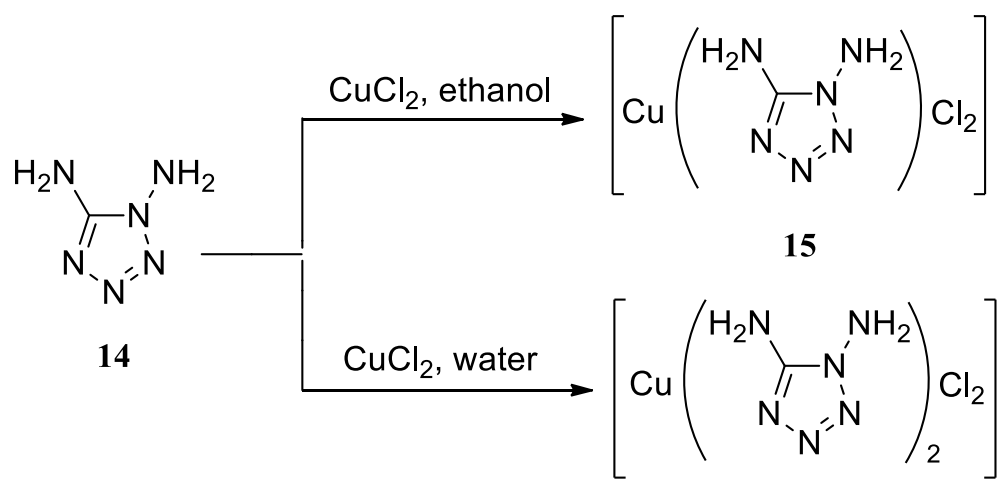

16

\section{Scheme 6}

In 1982 Franke described for the first time the tetrazole-containing complexes with Fe(II) whose magnetic properties were investigated in dependence on the temperature. It was shown that the reaction of iron(II) tetrafluoroborate with 1-alkyltetrazoles furnished octahedral iron complexes which suffered a reversible transition of a white high-spin form $\left({ }^{5} T_{2 \mathrm{~g}}\right)$ to a violet lowspin form $\left({ }^{1} A_{1 \mathrm{~g}}\right)$ at the temperature variation from 140 to $80 \mathrm{~K} \cdot{ }^{43} \mathrm{Up}$ till now the best-studied are the structure and the properties of hexacoordinated iron(II) complexes $\mathrm{FeL}_{6} \mathrm{X}_{2}$ that possess 
extremely high sensitivity of electronic characteristics to relatively weak external effects of the temperature, pressure or irradiation at a definite wave length. At present the properties of $\mathrm{Fe}$ (II) complexes with tetrazoles are extensively investigated (Scheme 7). ${ }^{44-50}$

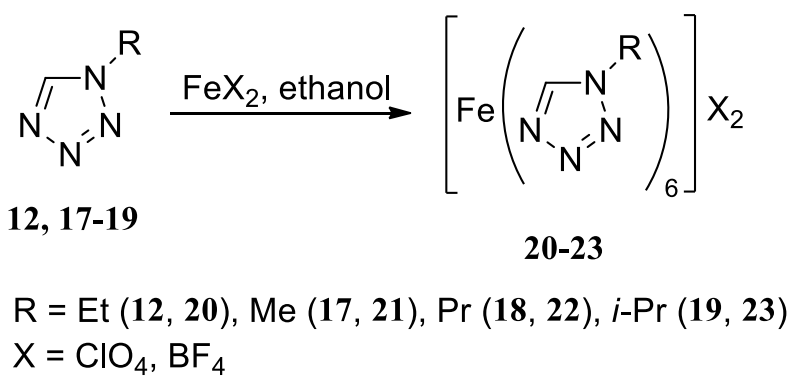

\section{Scheme 7}

Recently there has been much interest in coordination complexes containing in their structure binuclear $\mathrm{N}^{1}$-substituted tetrazoles. For instance, by the reaction of inorganic salts $\mathrm{MX}_{2}$ $(\mathrm{M}=\mathrm{Cu}(\mathrm{II}), \mathrm{Cd}(\mathrm{II}), \mathrm{Ni}(\mathrm{II}), \mathrm{Co}(\mathrm{II}) ; \mathrm{X}=\mathrm{Cl}, \mathrm{Br}, \mathrm{SCN})$ with 1,2-bis(tetrazol-1-yl)ethane 24 and 1,4bis(tetrazol-1-yl)butane 25 a series of new coordination polymers $\mathbf{2 6}, \mathbf{2 7} 7^{51}$ was obtained. The reactions of copper(II) salts with ditetrazoles led to the formation of coordination polymers possessing 3D structure (Scheme 8). X-Ray diffraction investigations showed that the copper atoms form $\mathrm{Cu}-\mathrm{N}$ bonds with $\mathrm{N} 4$ atoms of the tetrazole rings.

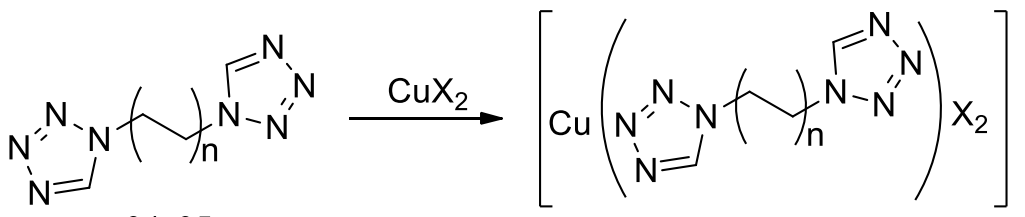

24,25

26, 27

$$
\mathrm{n}=1(\mathbf{2 4}, \mathbf{2 6}), 2(\mathbf{2 5}, \mathbf{2 7}) ; \mathrm{X}=\mathrm{Cl}, \mathrm{Br}
$$

\section{Scheme 8}

Liu et al. ${ }^{52}$ showed that the dimension number and the topology of Co(II) coordination polymers formed involving bis(tetrazole)alkyl ligands strongly depended on the length and the conformation of the alkyl spacers between the tetrazole rings.

\subsection{Reactions of $\mathbf{N}^{2}$-substituted tetrazoles with metal salts}

It was formerly believed that $\mathrm{N}^{2}$-substituted tetrazoles are not able to enter into complexes, but recent publications disproved this stereotype. 2-Substituted tetrazoles are more sensitive to the complexing conditions, in particular, to the presence of water in the reaction mixture. Besides the 
formation of solid coordinated $\mathrm{N}^{2}$-substituted tetrazoles is impeded by their good solubility. Therefore the synthesis of such complexes requires the high concentration of reagents and dry solvents; in some cases the reaction mixture should be heated and subsequently concentrated. When the $\mathrm{N}^{2}$-substituted tetrazoles are liquid it is possible to carry out the synthesis of the metal complexes by the reaction of the starting components without solvent. ${ }^{2}$

The most basic atom in the $\mathrm{N}^{2}$-substituted tetrazoles like in the $\mathrm{N}^{1}$-substituted derivatives is the nitrogen in the position 4 of the heterocycle (the basicity of the $\mathrm{N}^{2}$-substituted tetrazoles is somewhat lower than that of the corresponding $\mathrm{N}^{1}$-isomers ${ }^{1}$ ); therefore at the formation of the complexes the coordination bond exists mainly with the N4 nitrogen atom of the heterocycle.

For instance, in the reaction of 1,2-bis(tetrazol-2-yl)ethane with $\mathrm{Zn}\left(\mathrm{ClO}_{4}\right)_{2}$ a coordination polymer $\quad\left\{\left[\mathrm{Zn}\left(1,2-\operatorname{di}(1,2,3,4 \text {-tetrazol-2-yl)ethane })_{3}\right]\left(\mathrm{ClO}_{4}\right)_{2}\right\}_{\mathrm{n}}\right.$ was obtained. ${ }^{53}$ Besides the reaction between copper(II) chloride dehydrate and 2-methyltetrazole 28 furnished bis-(2methyltetrazole)dichlorocopper(II) 29 (Scheme 9). ${ }^{54}$ The crystallographic data showed that $\mathrm{Cu}$ atom environment presents an elongated octahedron with two 2-methyltetrazole ligands (N4bounded) and two $\mathrm{Cl}$ atoms in equatorial positions.

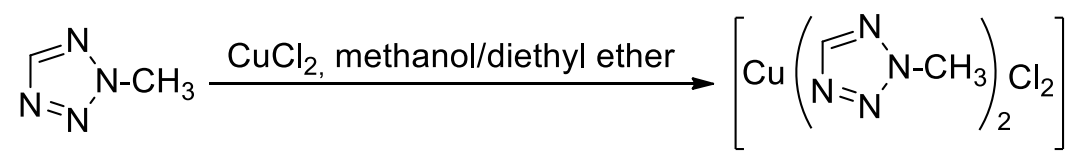

28
29

\section{Scheme 9}

The reaction of $\mathrm{Fe}\left(\mathrm{ClO}_{4}\right)_{2} \cdot 6 \mathrm{H}_{2} \mathrm{O}$ with 1,3-di(tetrazol-2-yl)propane gave coordination polymers $\quad\left\{\left[\mathrm{Fe}(1,3-\mathrm{di} \text { (tetrazol-2-yl)propane })_{3}\right]\left(\mathrm{ClO}_{4}\right)_{2} \cdot 2 \mathrm{EtOH}\right\}_{\mathrm{n}}$ and $\quad[\mathrm{Fe}(1,3-\mathrm{di}$ (tetrazol-2yl)propane $\left.\left.{ }_{3}\right]\left(\mathrm{ClO}_{4}\right)_{2}\right\}_{\mathrm{n}}{ }^{55}$ The tetrazole rings of 1,3-di(tetrazol-2-yl)propane coordinated to iron atoms through the endocyclic nitrogen atoms $\mathrm{N} 4, \mathrm{~N} 4$ ' form three-dimensional polymer nets.

2,5-Disubstituted tetrazoles are capable of the formation of coordination compounds with transition metal atoms, in particular, with the metals of the platinum group. For instance, by the reaction of 5-amino-2-tert-butyltetrazole with metal(II) chlorides complexes [Cu(2-tert-butyl-5aminotetrazole $\left.)_{3} \mathrm{Cl}_{2}\right], \quad\left[\mathrm{Pd}\left(2\right.\right.$-tert-butyl-5-aminotetrazole $\left.{ }_{2} \mathrm{Cl}_{2}\right], \quad[\mathrm{Pt}(2$-tert-butyl-5aminotetrazole) ${ }_{2} \mathrm{Cl}_{2}$ ] were obtained. ${ }^{56}$ The platinum complex exhibited cytotoxic activity with respect to tumor cells.

\section{Substitution of Ligands for Tetrazoles in Coordination Compounds}

A method for the preparation of tetrazole-containing complexes with anionic ligands consists of the substitution by tetrazole another ligand in a molecule of coordination compound (Scheme 10). ${ }^{57}$ This approach did not find a wide application in the synthesis of the tetrazole-containing metal complexes. 


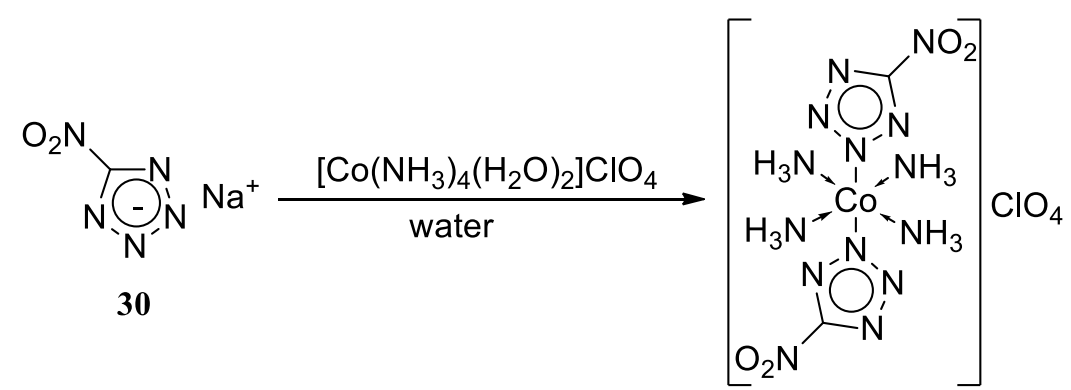

31

\section{Scheme 10}

\section{Metal-promoted Cycle Formation}

A fundamentally new approach to the preparation of tetrazole-containing coordination compounds was developed in 2001 by the Sharpless team. This method was initially developed for the synthesis of 5-substituted-1H-tetrazoles by simpler and more efficient procedure as compared to the classic conditions of 1,3-dipolar cycloaddition. The reaction involved inorganic azides and organic nitriles in the presence of $\mathrm{Zn}$ (II) salts under hydrothermal conditions (Scheme 11). ${ }^{58-61}$

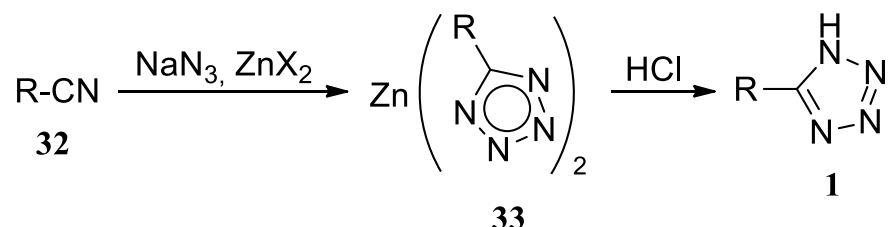

\section{Scheme 11}

This reaction goes through the stage of formation of tetrazolate ring coordinated to the zinc cation which were successfully isolated from the mixture. This approach was developed in a number of studies describing the synthesis of tetrazole-containing complexes under hydrothermal conditions (Scheme 12). ${ }^{62-65}$

According to data of X-ray diffraction, in these complexes multidentate ligands coordinate to metal atoms through different nitrogen atoms (N1, N2, N3, N4) of tetrazolyl groups what leads to formation of polymeric structures. The composition and the structure of complexes obtained can be varied depending on the reagents ratio and also on the acidity of the reaction mixture. It should be stressed that at the metal-promoted azidation of nitriles the arising complexes are also one-, two-, and three-dimensional coordination polymers. 


$$
\underset{34}{\mathrm{CH}_{3} \mathrm{CN}} \underset{\text { water/ethanol }}{\stackrel{\mathrm{NaN}_{3}, \mathrm{Zn}\left(\mathrm{ClO}_{4}\right)_{2}}{\longrightarrow}}\left[\mathrm { Zn } _ { 3 } \left(\mathrm{H}_{3} \mathrm{C}-\stackrel{\mathrm{N}-\mathrm{N}}{\mathrm{N}} \mathrm{N}\right.\right.
$$

35

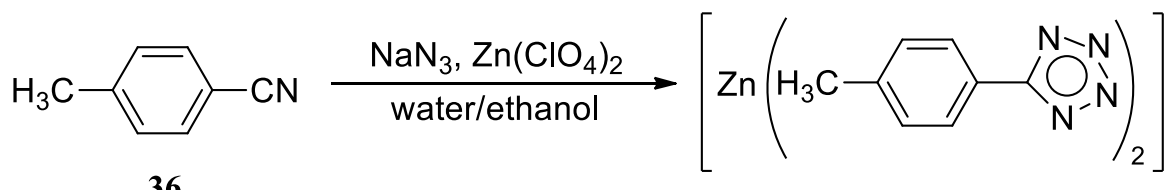

37

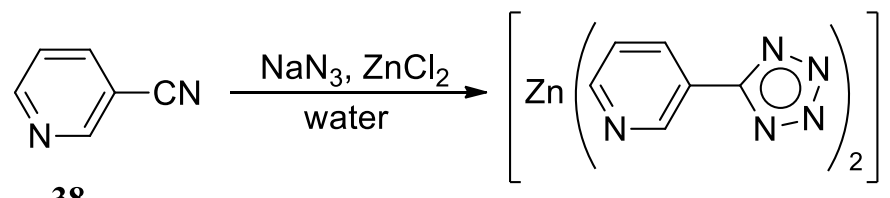

38

39

\section{Scheme 12}

Later publications appeared describing the synthesis of coordinated 5-substituted tetrazoles by azidation of nitriles in hydrothermal conditions in the presence of inorganic salts containing ions of $\mathrm{Cd}(\mathrm{II}), \mathrm{Cu}(\mathrm{II}), \mathrm{Hg}(\mathrm{II}), \mathrm{Ag}(\mathrm{I})$, etc. (Scheme 13).

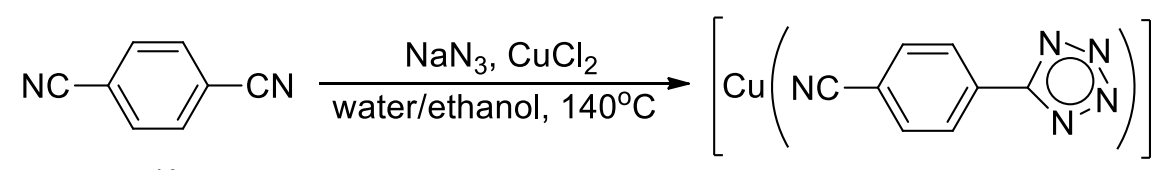

40

41

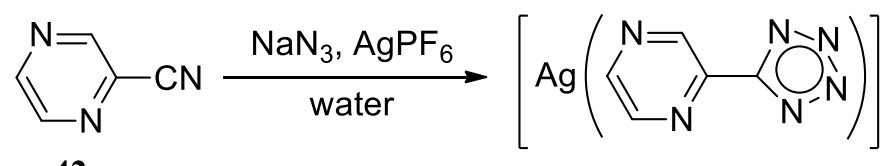

43

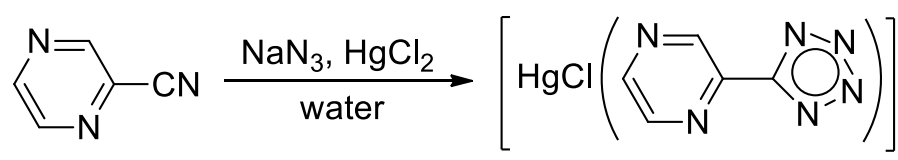

44

45

\section{Scheme 13}


Recently, numerous studies on the metal-promoted azidation of nitriles have been published. ${ }^{71-80}$ The range of metal salts applied to the preparation of the tetrazole-containing coordination compounds constantly grows. However their efficiency is variable. Thus the Sharpless team tested a series of metal salts (Li(I), K(I), Cs(I), Mg(II), Ca(II), Ba(II), Fe(II), $\mathrm{Co}(\mathrm{II}), \mathrm{Ni}(\mathrm{II}), \mathrm{Cu}(\mathrm{II}), \mathrm{Ag}(\mathrm{I}), \mathrm{Zn}(\mathrm{II}), \mathrm{Ce}(\mathrm{IV}), \mathrm{Sm}(\mathrm{III}), \mathrm{Yb}(\mathrm{III}), \mathrm{B}(\mathrm{III}), \mathrm{Al}(\mathrm{III}), \mathrm{Bi}(\mathrm{II}))$ in order to establish their capability to promote the formation of the tetrazole ring by azidation of nitriles, and it was found that the salts of these metals showed different promoting activity. ${ }^{59} \mathrm{~A}$ high efficiency in the formation of the tetrazole ring was exhibited by manganese(II) salts. $^{81}$ The mixing of equimolar amounts of $\mathrm{NaN}_{3}$ and cyanopyridines in the presence of $\mathrm{Mn}$ (II) salt in water-methanol mixture at room temperature led to the formation of the corresponding 5(pyridyl)-1H-tetrazoles in a stoichiometric yield (Scheme 14). Lin et al. ${ }^{81}$ stressed that in these reactions the $\mathrm{Mn}(\mathrm{II})$ salts are not catalysts but reagents involved in the formation of tetrazolecontaining complexes. The $\mathrm{Mn}$ (II) may be coordinated to the nitrogen atoms of the tetrazole rings as well as that of the pyridine ring or the cyano group. Thus, the 5-(2-pyridyl)tetrazolatoligand coordinates in a bidentate mode through the pyridyl nitrogen and N1 of the tetrazole ring, in complex 47.

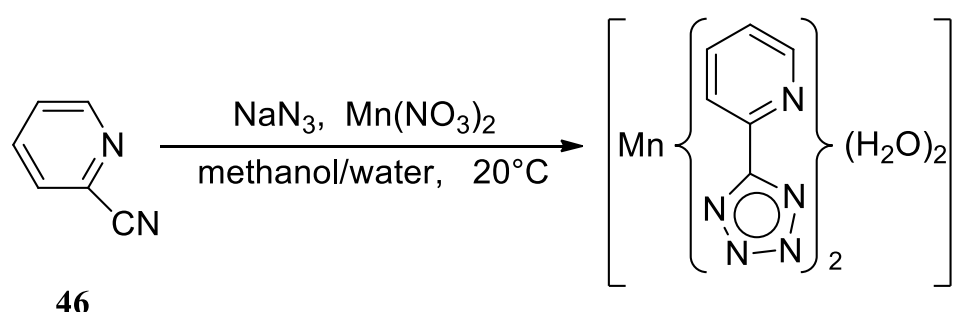

47

\section{Scheme 14}

It is important that in the case of 3,4-dicyanopyridine the azidation with sodium azide in the presence of $\mathrm{Mn}\left(\mathrm{NO}_{3}\right)_{2} \cdot 4 \mathrm{H}_{2} \mathrm{O}$ occurs at only one cyano group (Scheme 15$) .{ }^{81}$

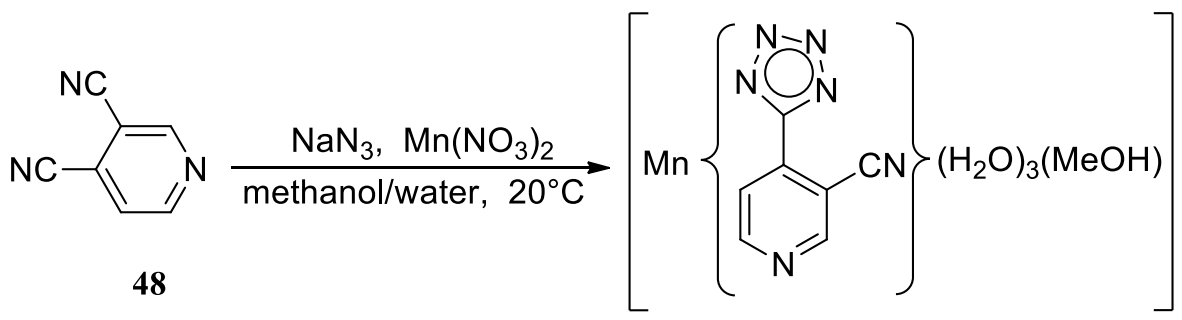

\section{Scheme 15}


By the same method from the corresponding nitriles and sodium azide in acetonitrile 14membered tetraazamacrocycles coordinated to $\mathrm{Ni}(\mathrm{II})$ and $\mathrm{Cu}(\mathrm{II})$ and containing two tetrazole rings were obtained and characterized. ${ }^{82}$ In the presence of triethylamine as a base the tetrazole rings are deprotonated (Scheme 16).

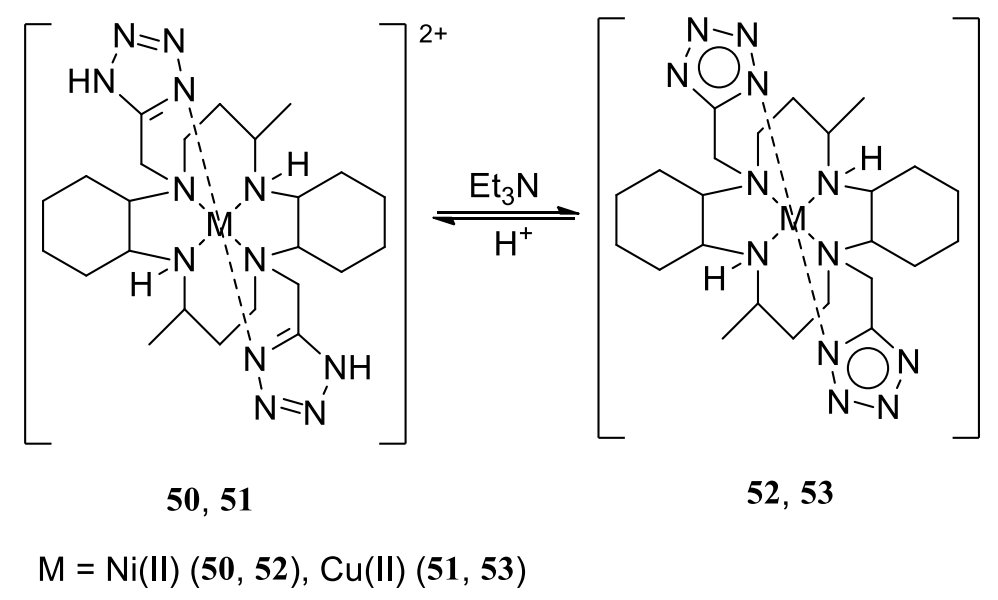

\section{Scheme 16}

Recently, an alternative method has been developed for the metal-promoted synthesis of coordinated tetrazoles, by the introduction into the reaction mixture of coordinated azides or nitriles. For instance, by reaction of nitriles $(\mathbf{3 4}, \mathbf{5 4 - 5 7 )}$ with coordination azides a series of tetrazolates coordinated to Pt(II) (58-62) were obtained (Scheme 17). ${ }^{83,84}$ In these processes the corresponding $\mathrm{N}(2)$-coordinated tetrazolates were selectively obtained. These reactions were shown to be accelerated under microwave irradiation.

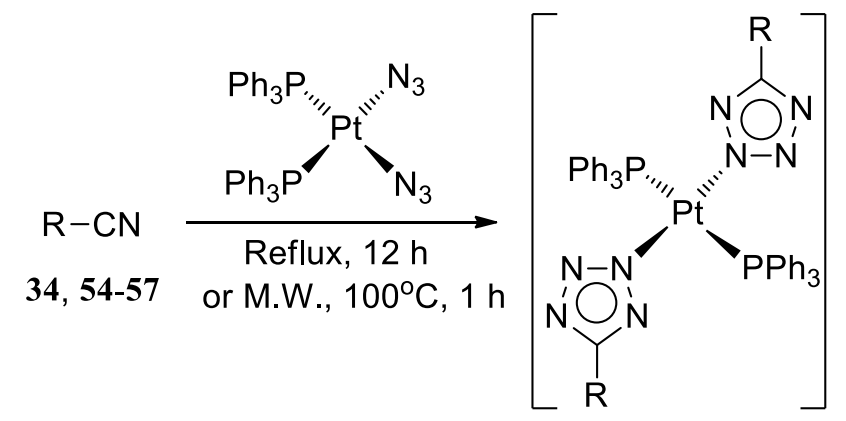

58-62

$\mathrm{R}=\mathrm{Me}(\mathbf{3 4}, \mathbf{5 8}), \operatorname{Et}(\mathbf{5 4}, \mathbf{5 9}), \operatorname{Pr}(\mathbf{5 5}, \mathbf{6 0}), \operatorname{Ph}(\mathbf{5 6}, \mathbf{6 1}), 4-\mathrm{ClC}_{6} \mathrm{H}_{4}(\mathbf{5 7}, \mathbf{6 2})$

\section{Scheme 17}

The preparation of a series of 5-alkyl- and 5-aryltetrazole-containing Mo(II) complexes 6568 from nitriles 34, 56, 63, 64 and azides coordinated to Mo(II) has been described ${ }^{85}$ (Scheme 
18). According to X-ray analysis the coordination of 5R-tetrazolate anion occurs at the $\mathrm{N} 2$ atom of the heterocycle.

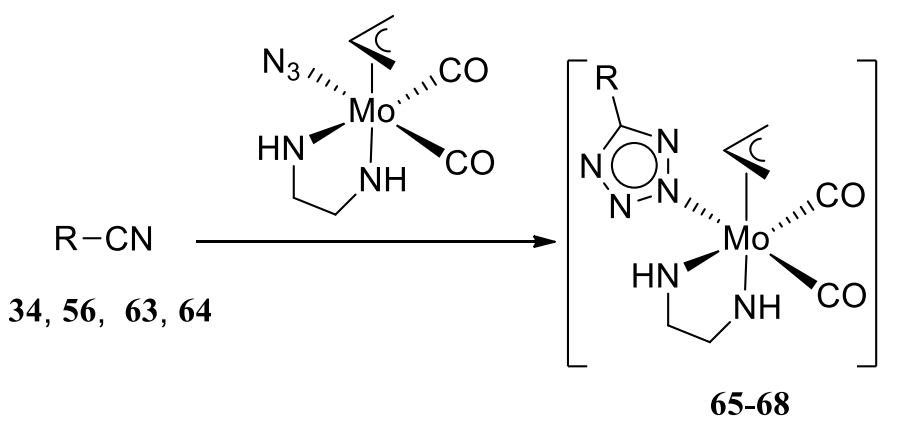

$\mathrm{R}=\mathrm{Me}(\mathbf{3 4}, \mathbf{6 5}), \mathrm{Vin}(\mathbf{6 3}, \mathbf{6 6})$, tert-Bu $(64,67), \mathrm{Ph}(56,68)$

\section{Scheme 18}

Some publications describe the synthesis of tetrazole-containing complexes by the azidation of coordinated nitriles. For instance, the reaction of binuclear complexes, 1,4-dicyanobenzenes coordinated to $\mathrm{Fe}(\mathrm{II})$ 69-71, with sodium azide in acetonitrile environment resulted in the azidation of one of the cyano groups (Scheme 19). ${ }^{86}$

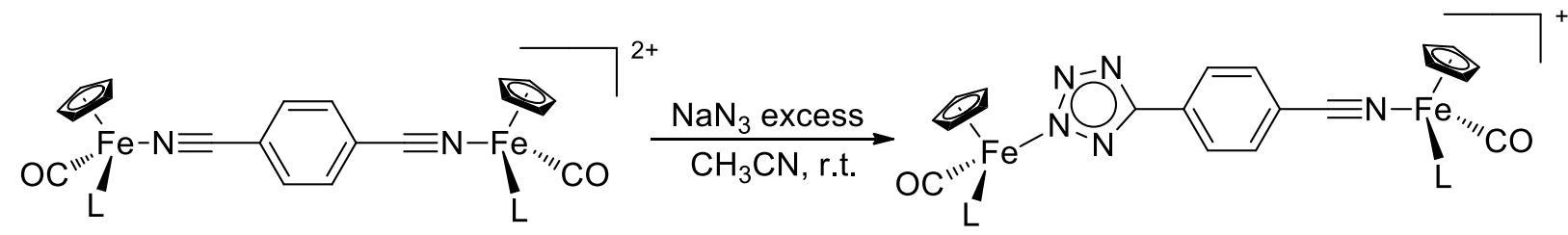

69-71

72-74

$$
\mathrm{L}=\mathrm{CO}(\mathbf{6 9}, \mathbf{7 2}), \mathrm{PPh}_{3}(\mathbf{7 0}, \mathbf{7 3}), \mathrm{P}(\mathrm{OMe})_{3}(\mathbf{7 1}, \mathbf{7 4})
$$

\section{Scheme 19}

It has been shown that the coordination of $\mathrm{RCN}$ to the metals of the platinum group considerably increased the nitrile reactivity in reactions with azides. ${ }^{87}$ For example, azidation of the nitriles coordinated to $\mathrm{Pt}(\mathrm{II})$ trans $-\left[\mathrm{PtCl}_{2}(\mathrm{RCN})_{2}\right]$ and $\mathrm{Pt}(\mathrm{IV})$ trans- $\left[\mathrm{PtCl}_{4}(\mathrm{RCN})_{2}\right](\mathrm{R}=\mathrm{Et}, \mathrm{Ph})$ 75-78 led to the formation of the corresponding tetrazolate complexes trans- $\left[\mathrm{PtCl}_{2}\left(\mathrm{RCN}_{4}\right)_{2}\right]^{2-} \mathbf{7 9}$, 80 and trans- $\left[\mathrm{PtCl}_{4}\left(\mathrm{RCN}_{4}\right)_{2}\right]^{2-} \mathbf{8 1}, 82$ with counterions $\mathrm{Ph}_{3} \mathrm{PCH}_{2} \mathrm{Ph}^{+}$and $\left(\mathrm{CH}_{3}\right)_{2} \mathrm{NH}_{2}{ }^{+}(\mathrm{Scheme}$ $20)$. In these compounds the coordination was found to involve the nitrogen atom $\mathrm{N} 1$. 


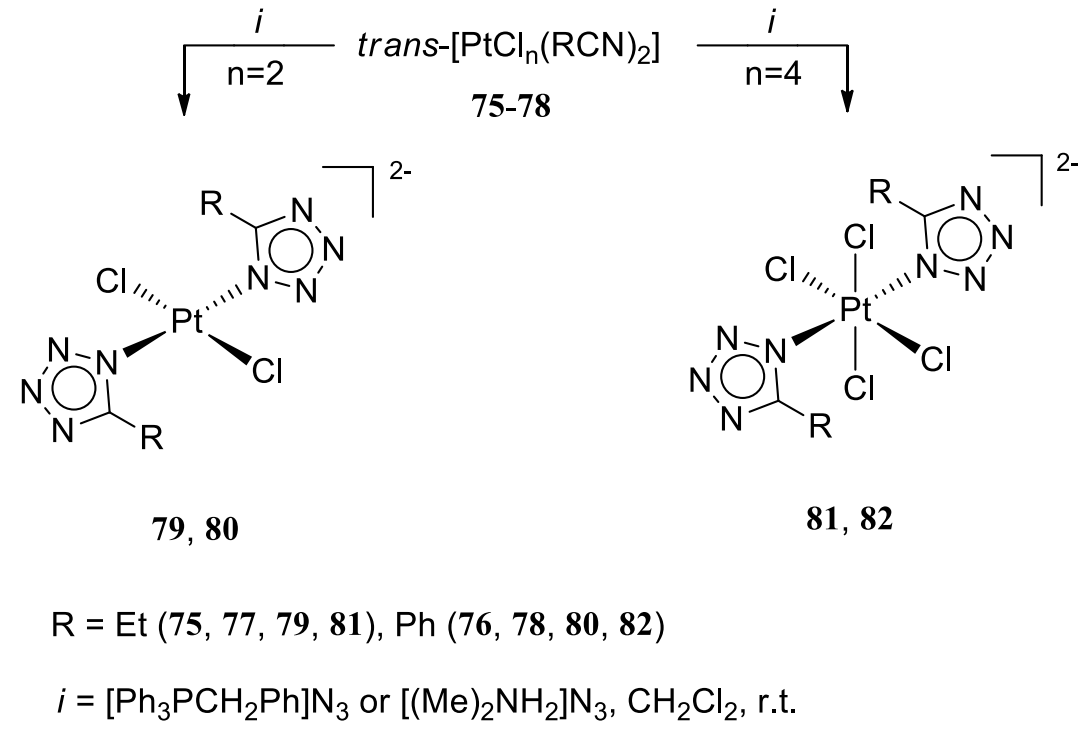

\section{Scheme 20}

Finally, an unusal method for the preparation of coordinated tetrazoles starting from the inorganic complex, bis(3-cyanopyridine)copper(II)azide 83, in the presence of Lewis acids $\mathrm{CuCl}_{2}$ and $\mathrm{CdCl}_{2}$ has been reported. ${ }^{88}$ As a result of these reactions homometallic 84 and heterometallic 85 complexes were obtained (Scheme 21). According to X-ray analysis these coordination polymers $\mathbf{8 4 ,} 85$ have a three-dimensional structure.

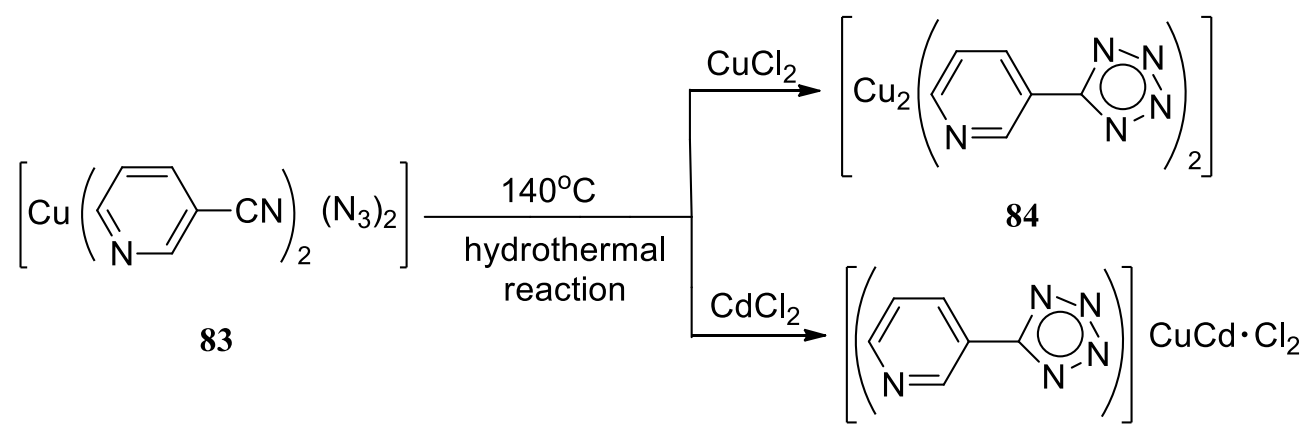

85

\section{Scheme 21}

\section{Conclusions}

The practical importance of tetrazoles and tetrazole-containing complexes and, at the same time, the unavailability of many compounds of this type, promoted the research directed to the development of new procedures for their targeted synthesis. It was demonstrated that the 
variation of procedures of preparation, the substrates used, and the synthesis conditions made it possible to obtain tetrazole-containing complexes of diverse compositions and structures. A significant success has recently been achieved in the development of efficient methods for the synthesis of tetrazole-containing complexes with various metals.

The authors are very much obliged to the Russian Fund for Basic Research (Grant 10-0300700-a).

\section{References}

1. Ostrovskii, V. A.; Koldobskii, G. I.; Trifonov, R. E. In Comprehensive Heterocyclic Chemistry III; Katritzky, A. R.; Ramsden, C. A.; Scriven, E. F. V.; Taylor, R. J. K. Eds.; Elsevier: Oxford. 2008, Vol. 6, p 257.

2. Gaponik, P. N.; Voitekhovich, S. V.; Ivashkevich, O. A. Russ. Chem. Rev. 2006, 75, 507.

3. Anacona, J. R.; Alvarez, P. Trans. Met. Chem. 2002, 27, 856.

4. Chohan, Z. H.; Supuran, C. T.; Scozzafava, A. J. Enzyme Inhibit. Med. Chem. 2004, 19, 79.

5. Ostrovskii, V. A.; Zubarev, V. Yu.; Putis, S. M.; Trifonov, R. E.; Popova, E. A. Pinchuk, L. S. Khimicheskaya Promyshlennost 2005, 82, 605.

6. Andreeva, N. P.; Kazanskiy, L. P.; Seljaninov, I. A.; Kuznetzov, Yu. I.; Ostrovskii, V. A. Korroziya: Materialy, Zashchita 2008, 12, 1.

7. Voitekhovich, S. V.; Gaponik, P. N.; Koldobskii, G. I. Russ. J. Org. Chem. 2005, 41, 1565.

8. Bhandari, S.; Mahon, M. F.; Molloy, K. C.; Palmer, J. S.; Sayers, S. F. J. Chem. Soc. Dalton Trans. 2000, 1053.

9. Brubaker, C. H. J. Am. Chem. Soc. 1960, 82, 82.

10. Daugherty, N. A.; Brubaker, C. H. J. Inorg. Nucl. Chem. 1961, 22, 193.

11. Daugherty, N. A.; Brubaker, C. H. J. Am. Chem. Soc. 1961, 83, 3779.

12. Jonassen, H. B.; Terry, J. O.; Harris, A. D. J. Inorg. Nucl. Chem. 1963, 25, 1239.

13. Harris, A. D.; Herber, R. H.; Jonassen, H. B.; Wertheim, G. K. J. Am. Chem. Soc. 1963, 85, 2927.

14. Labine, P.; Brubaker, C. H. J. Inorg. Nucl. Chem. 1971, 33, 3383.

15. Kieft, R. L.; Peterson, W. M.; Blundell, G. L.; Horton, S.; Henry, R. A.; Jonassen, H. B. Inorg. Chem. 1976, 15, 1721.

16. Takach, N. E.; Holt, E. M.; Alcock, N. W.; Henry, R. A.; Nelson, J. H. J. Am. Chem. Soc. 1980, 102, 2968.

17. Hubinger, S.; Hall, J. H.; Purcell, W. L. Inorg. Chem. 1993, 32, 2394.

18. Hall, J. H.; Purcell, W. L. Inorg. Chem. 1990, 29, 3806.

19. Hubinger, S.; Purcell, W. L. Inorg. Chem. 1991, 30, 3707.

20. Jackson, W. G.; Cortez, S. Inorg. Chem. 1994, 33, 1921.

21. Zhou, X.-G.; Huang, Z.-E.; Cai, R.-F.; Zhang, L.-X.; Hou, X.-F.; Feng, X.-J.; Huang, X.-Y. J. Organomet. Chem. 1998, 563, 101. 
22. Zhilin, A. Yu.; Ilyushin, M. A.; Tselinskii, I. V. Russ. J. Gen. Chem. 2001, 71, 664.

23. Gaponik, P. N.; Ivashkevich, O. A.; Krasitskii, V. A.; Tuzik, A. A.; Lesnikovich, A. I. Russ. J. Gen. Chem. 2002, 72, 1457.

24. Hill, M. S.; Hitchcock, P. B.; Smith, N. Polyhedron 2004, 23, 801.

25. Wang, Y.-C.; Zhao, H.; Song, Y.-M.; Wang, X.-S.; Xiong, R.-G. Appl. Organomet. Chem. 2004, 18, 494.

26. Tao, J.; Ma, Z.-J.; Huang, R.-B.; Zheng, L.-S. Inorg. Chem. 2004, 43, 6133.

27. Jiang, C.; Yu, Z.; Wang, S.; Jiao, C.; Li, J.; Wang, Z.; Cui, Y. Eur. J. Inorg. Chem. 2004, 18, 3662.

28. Kostakis, G. E.; Mondal, K. C.; Anson, C. E.; Powell, A. K. Polyhedron 2010, 29, 24.

29. Tong, X.-L.; Wang, D.-Z.; Hu, T.-L.; Song, W.-C.; Tao, Y.; Bu, X.-H. Cryst. Growth Des. 2009, 9, 2280.

30. Tao, Y.; Li, J.-R.; Chang, Z.; Bu, X.-H. Cryst. Growth Des. 2010, 10, 564.

31. Kostakis, G. E.; Anson, C. E.; Powell, A. K. Bioinorg. Chem. Applic. 2010, 5, doi:10.1155/2010/104329 (Article ID: 104329).

32. Klapötke, T. M.; Mayer, P.; Polborn, K.; Stierstorfer, J.; Weigand, J. J. New Trends in Research of Energetic Materials, Proccedings. 2006, 641.

33. Yang, G.-W.; Ma, Y.-S.; Li, Q.-Y.; Zhou, Y.; Gu, G.-Q.; Wu, Y.; Yuan, R.-X. J. Coord. Chem. 2009, 62, 1766.

34. Gilbert, G. L.; Brubaker Jr., C. H. Inorg. Chem. 1963, 2, 1216.

35. Franke, P. L; Groeneveld, W. L. Trans. Met. Chem. 1981, 6, 54.

36. Degtyarik, M. M.; Gaponik, P. N.; Naumenko, V. N.; Lesnikovich, A. I.; Nikanovich M. V. Spectrochimica Acta Part A. Molecular Spectroscopy 1987, 43, 349.

37. Poturovica, S.; Lua, D.; Heega, M. J.; Winter, C. H. Polyhedron 2008, 27, 3280.

38. Garber, L. L.; Brubaker Jr., C. H. J. Am. Chem. Soc. 1966, 88, 4266.

39. Soliman, A. A.; Khattab, M. M.; Linert, W. J. Coord. Chem. 2005, 58, 421.

40. Koningsbruggen, P. J.; Garcia, Y.; Bravic, G.; Chasseau, D.; Kahn, O. Inorg. Chimica Acta. 2001, 326, 101.

41. Shvedenkov, Yu.; Bushuev, M.; Romanenko, G.; Lavrenova, L.; Ikorskii, V.; Gaponik, P.; Larionov, S. Eur. J. Inorg. Chem. 2005, 9, 1678.

42. Gaponik, P. N.; Voitekhovich, S. V.; Lyakhov, A. S.; Matulis, V. E.; Ivashkevich, O. A.; Quesada, M.; Reedijk, J. Inorg. Chim. Acta. 2005, 358, 2549.

43. Franke, P. L.; Haasnoot, J. G.; Zuur, A. P. Inorg. Chim. Acta. 1982, $59,5$.

44. Muttenthaler, M.; Bartel, M.; Weinberger, P.; Hilscher, G.; Linert, W. J. Mol. Struct. 2005, $741,159$.

45. Schweifer, J.; Weinberger, P.; Mereiter, K.; Boca, M.; Reichl, C.; Wiesinger, G.; Hilscher, G.; Koningsbruggen, P. J.; Kooijman, H.; Grunert, M.; Linert, W. Inorg. Chim. Acta. 2002, 339, 297.

46. Koningsbruggen, P. J.; Garcia, Y.; Kooijman, H.; Spek, A. L.; Haasnoot, J. G.; Kahn, O.; Linares, J.; Codjovi, E.; Varret, F. J. Chem. Soc., Dalton Trans. 2001, 466. 
47. Grunert, C.M.; Schweifer, J.; Weinberger, P.; Linert, W.; Mereiter, K.; Hilscher, G.; Muller, M.; Wiesinger, G.; Koningsbruggen, P. J. Inorg. Chem. 2004, 43, 155.

48. Kusz, J.; Gütlich, P.; Spiering, H. Top. Curr. Chem. 2004, 234, 129.

49. Stassen, A. F.; Grunert, M.; Dova, E.; Müller, M.; Weinberger, P.; Wiesinger, G.; Schenk, H.; Linert, W.; Haasnoot, J. G.; Reedijk, J. Eur. J. Inorg. Chem. 2003, 2273.

50. Białońska, A.; Bronisz, R.; Weselski, M. Inorg. Chem. 2008, 47, 4436.

51. Yu, J.-H.; Mereiter, K.; Hassan, N.; Feldgitscher, C.; Linert W. Cryst. Growth Des. 2008, 8, 1535.

52. Liu, P.-P.; Cheng, A.-L.; Yue, Q.; Liu, N.; Sun, W.-W.; Gao, E.-Q. Cryst. Growth Des. 2008, $8,1668$.

53. Bronisz, R. Inorg. Chim. Acta. 2002, 340, 215.

54. Gaponik, P. N.; Degtyarik, M. M.; Lyakhov, A. S.; Matulis, V. E.; Ivashkevich, O. A.; Quesada, M.; Reedijk, J. Inorg. Chim. Acta. 2005, 358, 3949.

55. Bronisz, R. Inorg. Chem. 2007, 46, 6733.

56. Voitekhovich, S. V.; Serebryanskaya, T. V.; Lyakhov, A. S.; Gaponik, P. N.; Ivashkevich, O. A. Polyhedron 2009, 28, 3614.

57. Talawar, M. B.; Agrawal, A. P.; Asthana, S. N. J. Hazardous Materials 2005, 120, 25.

58. Demko, Z. P.; Sharpless, K. B. Angew. Chem. Int. Ed. 2002, 41, 2110.

59. Demko, Z. P.; Sharpless, K. B. J. Org. Chem. 2001, 66, 7945.

60. Himo, F.; Demko, Z. P.; Noodleman, L.; Sharpless, K. B. J. Am. Chem. Soc. 2003, 125, 9983.

61. Zhang X.-M. Coord. Chem. Rev. 2005, 249, 1201.

62. Wang, X.-S.; Tang, Y.-Z.; Huang, X.-F.; Qu, Z.-R.; Che, C.-M.; Chan, P.W.H.; Xiong, R.-G. Inorg. Chem. 2005, 44, 5278.

63. Wang, L.-Z.; Qu, Z.-R.; Zhao, H.; Wang, X.-S.; Xiong, R.-G.; Xue, Z.-L. Inorg. Chem. 2003, 42, 3969.

64. Mautner, F. A.; Gspan, C.; Gatterer, K.; Goher, M. A. S.; Abu-Youssef, M. A. M.; Bucher, E.; Sitte, W. Polyhedron 2004, 23, 1217.

65. Zhao, H.; Ye, Q.; Wu, Q.; Song, Y.-M.; Liu, Y.-J.; Xiong, R.-G. Z. Anorg. Allg. Chem. 2004, 630, 1367.

66. Tao, J.; Ma, Z.-J.; Huang, R.-B.; Zheng, L.-S. Inorg. Chem. 2004, 43, 6133.

67. Huang, X.-H.; Sheng, T.-L.; Xiang, S.-C.; Fu, R.-B.; Hu, S.-M.; Li, Y.-M.; Wu, X.-T. Inorg. Chem. Commun. 2006, 9, 1304.

68. Qiu, Y.; Li, Y.; Peng, G.; Cai, J.; Jin, L.; Ma, L.; Deng, H.; Zeller, M.; Batten, S.R. Cryst. Growth Des. 2010, 10, 1332.

69. Li, Z.; Li, M.; Zhou, X.-P.; Wu, T.; Li, D.; Ng, S. W. Cryst. Growth Des. 2007, 7, 1992.

70. Qiu, Y.; Liu, B.; Peng, G.; Cai, J.; Deng, H.; Zeller, M. Inorg. Chem. Commun. 2010, 13, 749.

71. Wu, T.; Yi, B.-H.; Li, D. Inorg. Chem. 2005, 44, 4130. 
72. Ye, Q.; Li, Y.-H.; Song, Y.-M.; Huang, X.-F.; Xiong, R.-G.; Xue, Z. Inorg. Chem. 2005, 44, 3618.

73. Bosch, L.; Vilarrasa, J. Angew. Chem. Int. Ed. 2007, 46, 3926.

74. Deng, H.; Qiu, Y.-C.; Li, Y.-H.; Liu, Z.-H.; Zeng, R.-H.; Zeller, M.; Batten, S. R. Chem. Commun. 2008, 2239.

75. Zhao, H.; Qu, Z.-R.; Ye, H.-Y.; Xiong, R.-G. Chem. Soc. Rev. 2008, 37, 84.

76. Fu, D.-W.; Zhang, W.; Xiong, R.-G. Cryst. Growth Des. 2008, 8, 3461.

77. Song, W.-C.; Li, J.-R.; Song, P.-C.; Tao, Y.; Yu, Q.; Tong, X.-L.; Bu, X.-H. Inorg. Chem. 2009, 48, 3792.

78. Huang, Y.; Chen, L.-Z.; Xiong, R.-G.; You, X.-Z. Inorg. Chim. Acta 2010, 363, 2512.

79. Sengupta, O.; Mukherjee, P. S. Inorg. Chem. 2010, 49, 8583.

80. Singh, S.; Mayer, P.; Pandey, A. Ind. J. Chem. 2010, 49, 1345.

81. Lin, P.; Clegg, W.; Harrington, R. W.; Henderson, R. A. Dalton Trans. 2005, 14, 2388.

82. Kang, S.-G.; Kim, H.; Kim, N.; Jeong, J. H. Bull. Korean Chem. Soc. 2009, 30, 3101.

83. Mukhopadhyay, S.; Lasri, J.; Charmier, M. A. J.; da Silva, M. F. C. G.; Pombeiro, A. J. L. Dalton Trans. 2007, 5297.

84. Smoleński, P.; Mukhopadhyay, S.; da Silva, M. F. C. G.; Charmier, M. A. J.; Pombeiro, A. J. L. Dalton Trans. 2008, 6546.

85. Liu, F.-C.; Lin, Y.-L.; Yang, P.-S. Organometallics 2010, 29, 4282.

86. Palazzi, A.; Stagni, S. J. Organomet. Chem. 2005, 690, 2052.

87. Popova E. A., Bokach N. A., Haukka M., Trifonov R. E., Ostrovskii V. A. Inorg. Chim. Acta. 2011, 375, 242.

88. Tang, Y.-Z.; Wang, G.-X.; Ye, Q.; Xiong, R.-G.; Yuan, R.-X. Cryst. Growth Des. 2007, 7, 2382

\section{Authors' Biographies}

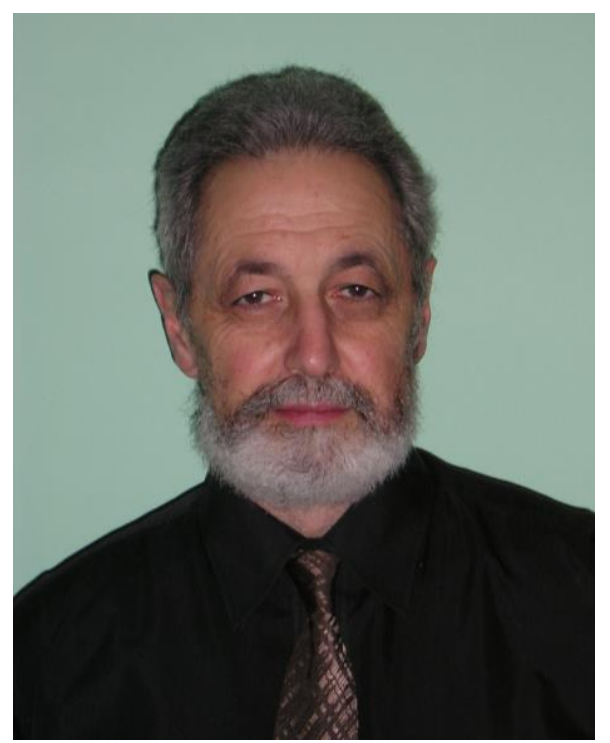


Vladimir Aronovich Ostrovskii: was born in 1947. He graduated from the Leningrad Technological Institute in 1971. He is Candidate of the Chemical Science since 1976 and Doctor of the Chemical Sciences since 1985. V. Ostrovskii is Professor at the Chair of the Chemistry and Technology of Nitrogen Organic Compounds of the St. Petersburg State Institute of Technology (Technical University) since 1992. He is author of over 300 scientific publications. The field of his scientific interests is the synthesis, physicochemical properties and reactivity of nitrogen-containing heterocycles.

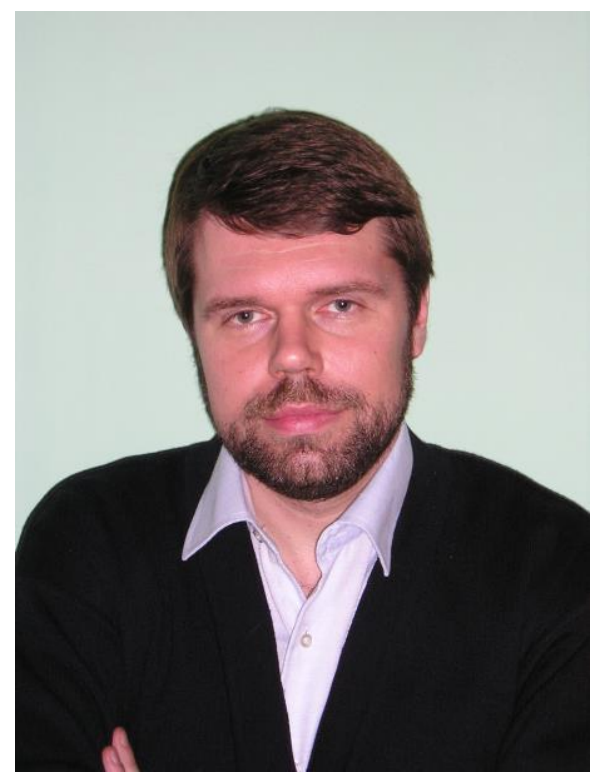

Rostislav Evgenevich Trifonov: was born in 1969. He graduated from the St. Petersburg State Institute of Technology in 1994. He is Candidate of the Chemical Science since 1999 and Doctor of the Chemical Sciences since 2007. R. Trifonov is Professor at the Chair of the Chemistry and Technology of Nitrogen Organic Compounds of St. Petersburg State Institute of Technology (Technical University) since 2007. He is author of over 100 scientific publications. The field of his scientific interests is the synthesis, the physicochemical properties and reactivity of nitrogen-containing aromatic heterocycles. 


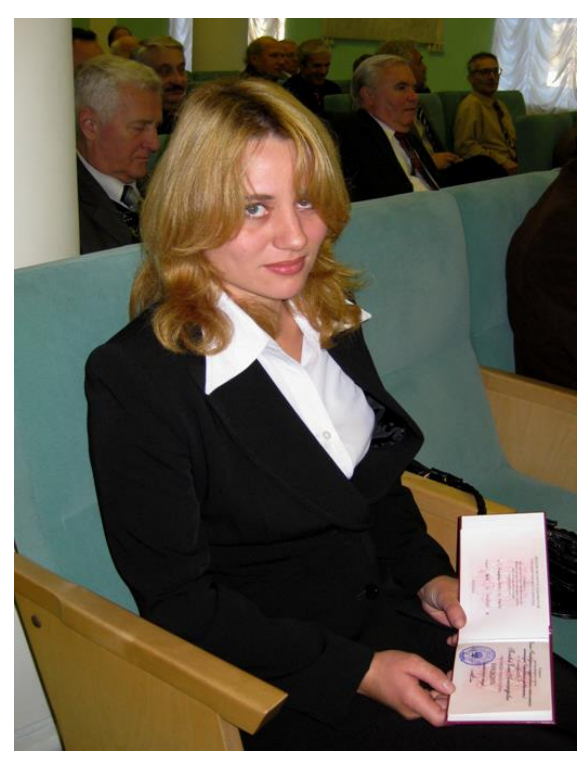

Elena Aleksandrovna Popova: was born in 1979. She graduated from the St. Petersburg State Institute of Technology in 2004. She is Candidate of the Chemical Science since 2007. E. Popova is scientific researcher at the Chair of the Chemistry and Technology of Nitrogen Organic Compounds of St. Petersburg State Institute of Technology (Technical University) since 2004. The field of her scientific interests is the synthesis, the physicochemical properties and reactivity of tetrazoles and tetrazole-containing complexes. 